\title{
WORD-SOUND THERAPY AS AN INTERVENTION TO IMPROVE PHONOLOGICAL AWARENESS: CASE STUDY ON A CHILD WITH PHONOLOGICAL DISORDER
}

\author{
Sessiani, L.A. \\ Universitas Islam Negeri Walisongo Semarang, Indonesia
}

\section{A R T I C L E IN F O Article history: \\ Received 19 March 2018 \\ Received in revised form 12 April \\ Accepted 16 May 2018 \\ Available online 25 June 2018 \\ Keywords: \\ Word-sound Therapy, \\ Phonological Awareness, \\ Phonological Disorder}

\begin{abstract}
A B S T R A C T
Phonological awareness is ability to segment the syllables and phonemes heard in speech. It is also the most important behavioral index to measure the development of reading skill. Children who had problems or impairments in phonological awareness will perform high-risk for reading skill mastery which is the most important skill in early education level. The current study aims to evaluate the effect of Word-Sound Therapy in improving phonological awareness and speech production in single word segment level. The subject of the study is a child, 5 years of age, who met the diagnostic criterias for Phonological Disorder according to Diagnostic and Statistical Manual of Mental Disorders (DSM-IV-TR). The WordSound Therapy is used as an intervention which include series of phonological awareness tasks and inserting the speech production training between the phonological awareness activities to improve phonemic awareness. This research is using a multiple baseline across behavior design. The qualitative data analysis was conducted using behavioral approach, Response Antecedents Consequences-Strength (RAC-S). Visual inspection was also used to observe the emergence of target behaviors. Result showed that Word-Sound Therapy is improving child's ability in identifying similarity and analyze the last phoneme in words. Result also showed that this therapy could be used for children at minimum 5 years of age, had normal $\mathrm{IQ}$, and needs a phonological awareness intervention especially focused in rhyme detection and last phoneme isolation.
\end{abstract}

\section{Introduction}

Phonology is a cognitive representation of speech sounds, it plays a central role in reading development. The behavioral index of these developing representations is phonological awareness, measured as the ability to segment the syllables and phonemes heard in speech (e.g., say /stop/ without the /s/). Although this indicator of phonological processing ability involves only spoken language, phonological awareness in early-aged children predicts reading achievement at the later age, and according to National Institute of Child Health and Human Development, phonologically based reading interventions precipitate gains in reading achievement (Ashby, 2010).

Children who first learn to read will learn to recognize word. Word recognizing stages in reading development are logographic, alphabetic, and orthographic stage. In logographic stage, a child should master the ability to decode word. It will be used to form the connection between the shape and sound of letters in alphabetic stage. The decoding ability indicates that the child has a good phonological awareness (PA) (Westwood, 2001). The term awareness refers to a condition when a child is truly understood that spoken language consist of words. Each word itself consists of syllables, and syllables consist of separate individual sounds (phonemes). Children know language only from daily conversation, therefore the concept of a word having separate sounds and language has a printed form, is not completely understood yet. The forming of this concept of word is the initial step to improve the child awarenes about the phonological structure of language, which is the prerequisite to teach the next concept, alphabetic (Westwood, 2001). As a prerequsite for the reading ability, PA has been considered as a basic skill to 
master in early reading process and it has been an important factor that predict the reading success in school-age children (Byrnes, 1996; Holm, 2008; Picard, 2002; Rvachew \& Grawburg, 2006; Snowling \& Stackhouse, 2006). PA is also considered as the main causal factor in many case of reading difficulties (Grainger, 2003; Westwood, 2001).

Children who have difficulties in speech, language, and communication can also have difficulties in literacy, including reading, writing, speaking, hearing, and thinking (Picard, 2002). Based on the research result, Sutherland and Gillon (2005) showed that children with speech disorders having a lower phonological representation than children with normal speech development. The phonological processing difficulty in these children could still be existing until the next years, when they enter the higher academic level and should have master the phonological skill (Rvachew, 2007). Research demonstrates a progression in the order in which children acquire phonological awareness, such that awareness of larger speech segments (words, syllables) precedes awareness of smaller segments (onset-rimes, phonemes) (Goswami, 1999; Lonigan, Burgess, Anthony, \& Baker, 1998; Schuele \& Boudreau, 2008, in HipfnerBoucher, et.al, 2014).

Phonological disorder (PD) is often called articulation disorder, developmental articulation disorder, or speech sound production disorder. The term developmental phonological disorder is used when the disorder happens with no clear cause and no neurological problem found (Davidson, 2003). In Indonesia, the prevalence of this disorder is argueable and rarely documented. Professional Working Practice in the Faculty of Psychology Gadjah Mada University founded 2 students who had PD in kindergarten, and 2 other in elementary school. These researches take place in two different kindergarten and elementary school in Yogyakarta (Puspitasari, 2010; Sessiani, 2010; Wulansari, 2009).

Children with PD failed to use developmentally expected speech sounds that are appropriate for their age and dialect. There are errors in speech, such as saying "susu" as "cucu" (DSM-IV-TR, APA, 2000). It is different with speech defectnown as "cadel" which characterized by pronouncing / $\mathrm{r} /$ as /l/ (KBBI, 1999). The form of speech errors in phonological disorder could manifest as subtitution, omission, distortion, indistinct, and addition (Judarwanto, in Wulansari, 2009). Children with phonological impairments do not necessarily go on to experience literacy problems, but children who still have phonological disability in the form of speech errors when they start school, are very much at risk for difficulties learning to read and spell. This is one reason why they should be treated in early years of age (Bowen, 1998).

The research conduct by Gillon (2000) is one of five researches with the most effective PA intervention method for children with speech disorder (Cirrin dan Gillam, 2008). The Gillon Phonological Awareness Training is the program that Gillon (2000) used for her research. McNeill, Gillon, and Dodd (2009) then improving this program and called it The Gillon and McNeill Integrated Phonological Awareness Programme (2007). This program consists of PA practices in a more brief and integrated form including speech therapy and letter knowledge for subjects with apraxia. This program focused on phonological representation and practicing speech in order to improve PA and speech production simultaneously.

The Gillon and McNeill Integrated Phonological Awareness Programme (2007) facilitate the participants of McNeill, Gillon dan Dodd (2009) to have a visual-verbal paired associated learning. The participants get a word-konwledge practice using pictures to identify and mention the initial and last phoneme in words. They also get practice in letter-sound knowledge. Result showed that this program is effective and simultaneously improved speech production, PA, word decoding, and spelling in subjects with apraxia of speech. The effectiveness of this intervention program gives an adequate scientific evidence to implement this program to children with PD.

So far, there is no published research in Indonesia that suggest a form of effective intervention program to improve reading ability or PA especially for children with PD. Due to this particular reason, this research aims to give an intervention program through a PA training for a child with PD. This training is adapted from The Gillon and McNeill Integrated Phonological Awareness Programme (2007) which is used in McNeill, Gillon dan Dodd's research on 2009. The training contains material from several aspects of PA: rhyme detection, phoneme identity, initial phoneme isolation and last phoneme isolation. The purpose of this study is to understand the effect of Word-Sound Therapy to improve PA ability and to decrease speech/articulation errors on a single word segment level. 


\section{Methods}

\section{Participant}

The subject of this research is a boy, 5 years of age, who diagnosed having speech delay by Child Development Centre on his age of 3. He was never had speech/language therapy before. There are several academic problems such as difficulty to follow activities that demand verbal ability (story telling, mentioning word, singing, ang copying teacher's instruction). The academic and behavior problems either in school or home emerged as the impact of the disorder he had.

Subject qualifies the diagnostic criteria of DSM IV-TR (APA, 2000) for Phonological Disorder. His IQ is on the normal range, 107, with the mental age equivalent 4 years and 10 months (tested when aged 4 years and 6 months). Based on the test observation, subject is easier to respond test items which need comprehension and demand less speech ability. But he is difficult to respond the test items which demand spoken language ability such as picture story telling, making a definition, noun similarity, or making a reason.

The Response Antecendents Consequences-Strength (RAC-S) data are explained as follows:

Target response: Based on the baseline data, the low PA ability is more likely happens in two aspect, in identifying and determining the last phoneme in word. In the last one year, based on observation, the lack of PA is affected by the articulation errors subject had. The articulation errors were dominant in last phoneme pronounciation especially $/ \mathrm{k} /, / \mathrm{l} /, / \mathrm{n} /, / \mathrm{ng} /, / \mathrm{s} /$, and $/ \mathrm{t} /$ which mostly lost or not clearly heard. Antecedents: Subject had a history on speech delay (identified in the age of 3). When he entered school, his parents were more concerned about his self-confidence and self-adjustment toward friends, teachers, and school tasks. The articulation errors happen when he is talking is often being tolerated by his parent.

Consequences: Negatives: (1) The speech errors are causing errands in dealing with the school task which needs PA ability. (2) Subject had not realized that he made mistake when speaking, and also he felt that he didn't need to correct his speech. Positive: subject has an adequate sef confidence and spoke a lot when interracting with the significant other at home because he felt understood.

Response strength: Speech errors occured since subject was 3 years old. The academic problems related with PA identifiied since subject was in the first year of kindergarten (on A class, age 4 years old or more).

\section{Treatment}

Intervention was given in 2 area, each of it aims to improve PA and decrease speech/articulation errors in single word level. The treatment conducted by therapy and training method consisting PA material and inserting speech therapy procedure in each meeting. Treatment was lead by a trainer who met these qualifications below:

a. Having an adequate competence in treating children's academic and reading problems.

b. Quaified as a speech therapist (having several experience in treating children's speech difficulties).

\section{Measurement}

The effect of the intervention will measured by observing the baseline and posttest data using the test adapted from Phonological Awareness Assessment Probes (Gillon, 2007). The PA test comprise of 4 subtests which conducted parallel and have equal number of items.

\section{Research Design}

This research is using multiple-baseline across behavior design. It is a design commonly used for single subject research which enables multiple measurements on more than two target behavior (Sundel \& Sundel, 2005). The design was chosen because researcher then can analyze the efficacy of the intervention procedure toward subject through several target behaviour at once (Blischak, dkk, 2004).

\section{Method of Data Analysis}

Visual inspection used in this study aims to observing the graphic that describe the PA ability represent in 4 different test results. It is enable the researcher to determine whether there is a change on subject in each behavior target (Sundel \& Sundel, 2005). The analysis of change between and within 
condition refers to the visual inspection analysis for single subject research by Sunanto, Takeuchi, and Nakata (2005). Qualitative data analysis using Response Antecendents Consequences-Strength (RAC-S) by Sundel and Sundel (2005) is also done to observe the behavior change after the intervention

\section{Findings and Discussion}

The baseline and training phase have been done in 8 meeting. Each meeting took about 90 minutes of time with various topics continued by follow up phase, 4 weeks after the therapy finished. Total data collection from the baseline until follow up going on about 1.5 month.

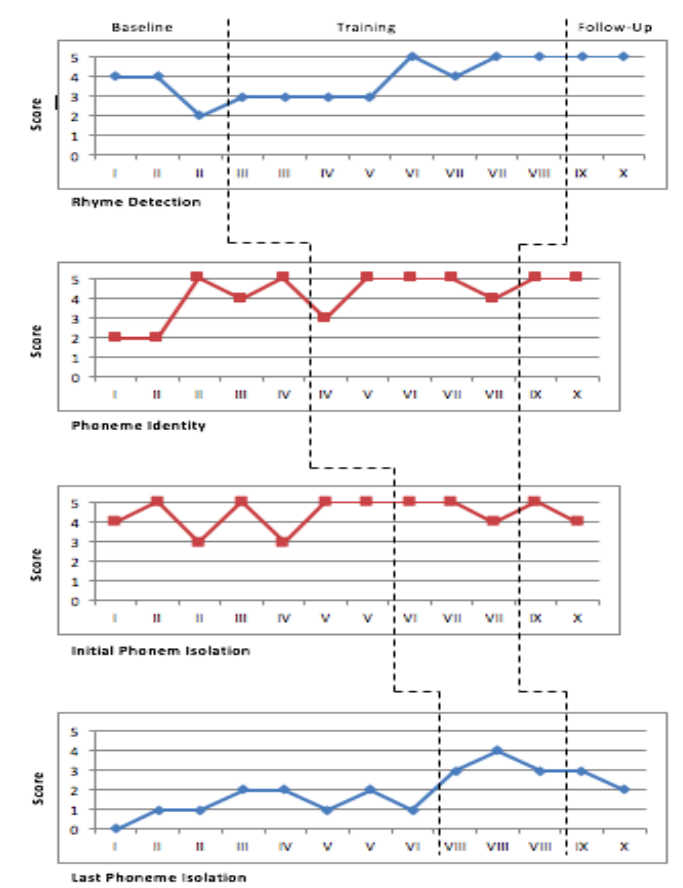

Figure 1. Subject's score on each phonological awareness aspects during baseline, training, and follow-up

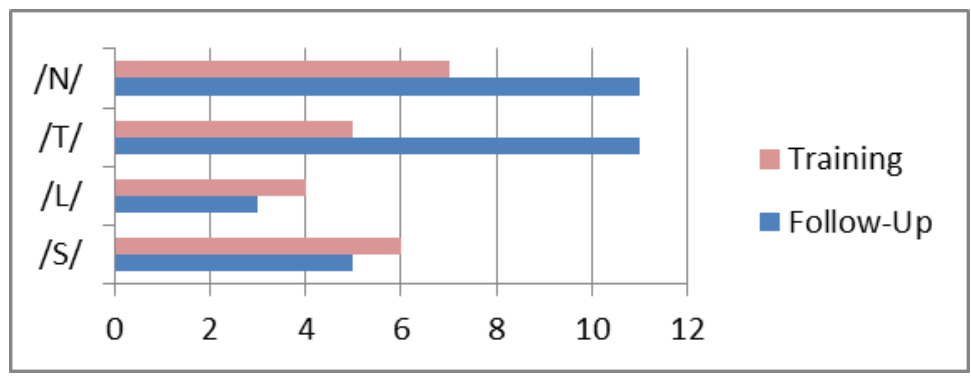

Figure 2. Average number of trial for words contain phonemes pronounced correctly during training and follow-up

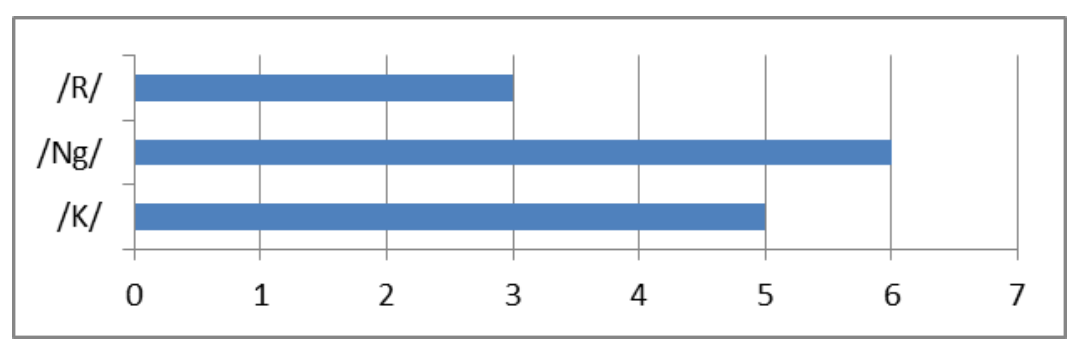

Figure 3. Average number of trial for words contain phonemes pronounced uncorrectly during training

Data score in four of the PA aspects analyzed by using simple statistic descriptive technique. Visual analysis for the individual data have done by paying attention to how many point (score) in each 
condition, quantity of dependent variable, stability level, level of data change between condition, and also level of data change within condition (Sunanto, Takkeuchi, \& Nakata, 2005). The result summary of visual analysis within and between conditions showed on table 1 and table 2 .

Table 1. Visual analysis result (within condition)

\begin{tabular}{|c|c|c|c|c|c|c|c|c|}
\hline \multirow{2}{*}{$\begin{array}{l}\text { Aspect } \\
\text { Condition }\end{array}$} & \multicolumn{2}{|c|}{ Rhyme Detection } & \multicolumn{2}{|c|}{ Phoneme Identity } & \multicolumn{2}{|c|}{$\begin{array}{l}\text { Initial Phoneme } \\
\text { Isolation }\end{array}$} & \multicolumn{2}{|c|}{$\begin{array}{l}\text { Last Phoneme } \\
\text { Isolation }\end{array}$} \\
\hline & B & $\mathbf{T}$ & B & $\mathbf{T}$ & B & $\mathbf{T}$ & B & $\mathbf{T}$ \\
\hline $\begin{array}{l}\text { Length of } \\
\text { condition }\end{array}$ & 3 & 8 & 5 & 5 & 7 & 3 & 8 & 3 \\
\hline \multirow{2}{*}{$\begin{array}{l}\text { 2. Estimation of } \\
\text { direction's } \\
\text { trend }\end{array}$} & & & & & & & & \\
\hline & $(-)$ & $(+)$ & $(+)$ & $\Leftrightarrow$ & $\Leftrightarrow$ & $(-)$ & $(+)$ & $(=)$ \\
\hline $\begin{array}{l}\text { 3. Trend of } \\
\text { stability }\end{array}$ & Stable & Stable & Variable & Stable & Stable & Stable & Stable & Stable \\
\hline $\begin{array}{l}\text { 4. Range of } \\
\text { stability }\end{array}$ & $(2-4)$ & $(3-5)$ & $(2-5)$ & $(3-5)$ & $(3-5)$ & $(4-5)$ & $(0-2)$ & $(3-4)$ \\
\hline 5. Change level & $\begin{array}{l}2-4 \\
(-2)\end{array}$ & $\begin{array}{c}5-3 \\
(+2) \\
\end{array}$ & $\begin{array}{c}5-2 \\
(+3) \\
\end{array}$ & $\begin{array}{c}4-3 \\
(+1)\end{array}$ & $\begin{array}{c}5-4 \\
(+1)\end{array}$ & $\begin{array}{l}4-5 \\
(-1)\end{array}$ & $\begin{array}{c}1-0 \\
(+1)\end{array}$ & $\begin{array}{c}4-3 \\
(+1)\end{array}$ \\
\hline
\end{tabular}

* B: Baseline T: Training

1. Rhyme detection
a. There are 3 baseline and 8 post training measurements.
b. The change level trend is descending on baseline and arises after the training was given.
c. The change level in baseline is descending 2 points, and ascending 2 points post training.

2. Phoneme identity
a. There are 5 baseline and 5 post training measurements.
b. The change level trend continues to arise during baseline and after the training was given.
c. The change level in baseline is ascending 3 points, and ascending 1 point post training.

3. Initial phoneme isolation
a. There are 7 baseline and 3 post training measurements.
b. The change level trend continues to arise during baseline and decreasing after the training was given.
c. The change level in baseline is ascending 1 point, and descending 1 point post training.

4. Last phoneme Isolation
a. There are 8 baseline and 3 post training measurements.
b. The change level trend continues to arise during baseline and after the training was given.
c. The change level in baseline is ascending 1 point, and ascending 1 point post training.

Table 2. Visual analysis result (between condition)

\begin{tabular}{|c|c|c|c|c|}
\hline Compared condition & $\begin{array}{c}\text { Rhyme Detection } \\
\text { B/T }\end{array}$ & $\begin{array}{c}\text { Phoneme Identity } \\
\text { B/T }\end{array}$ & $\begin{array}{c}\text { Initial Phoneme } \\
\text { Isolation } \\
\text { B/T }\end{array}$ & $\begin{array}{c}\text { Last Phoneme } \\
\text { Isolation } \\
\text { B/T }\end{array}$ \\
\hline $\begin{array}{l}\text { Number of dependent } \\
\text { variable }\end{array}$ & 1 & 1 & 1 & 1 \\
\hline $\begin{array}{l}\text { 2. Change of direction \& } \\
\text { effect }\end{array}$ & $\begin{array}{l}(-) \rightarrow(+) \\
\text { Positive }\end{array}$ & $\begin{array}{l}(+) \rightarrow(=) \\
\text { Negative }\end{array}$ & $\begin{array}{l}(=) \rightarrow(-) \\
\text { Negative }\end{array}$ & $\begin{array}{l}(+) \rightarrow(=) \\
\text { Positive }\end{array}$ \\
\hline 3. Change of stability & Stable $\rightarrow$ Stable & Variable $\rightarrow$ Stable & Stable $\rightarrow$ Stable & Stable $\rightarrow$ Stable \\
\hline 4. Change of level & $\begin{array}{l}(2-3) \\
+1\end{array}$ & $\begin{array}{c}(5-3) \\
-2\end{array}$ & $\begin{array}{c}(5-5) \\
0\end{array}$ & $\begin{array}{l}(1-3) \\
+2\end{array}$ \\
\hline $\begin{array}{l}\text { 5. Number of overlap data: } \\
\text { total of data }\end{array}$ & $5: 8$ & $2: 5$ & $3: 3$ & $0: 3$ \\
\hline
\end{tabular}

* B: Baseline $\quad$ T: Training

The visual analysis result (between conditions) on each PA aspect showed that:

1. Rhyme detection

a. The change of the direction from baseline until training showed that the training gives

positive effect toward the score change. 
b. The increasing level (observed from the last baseline until the first post training measurement) is 1 point.

c. There are 5 overlap data (post training score equal with baseline score) from 8 data in post training.

2. Phoneme identity

a. The change of the direction from baseline until training showed that the training gives negative effect toward the score change.

b. The decreasing level (observed from the last baseline until the first post training measurement) is 2 point.

c. There are 2 overlap data (post training score equal with baseline score) from 5 data in post training.

3. Initial phoneme isolation

a. The change of the direction from baseline until training showed that the training gives negative effect toward the score change.

b. The level of change (observed from the last baseline until the first post training measurement) is $\mathbf{0}$ point (the trend is likely static).

c. There are 3 overlap data (post training score equal with baseline score) from 3 data in post training.

4. Last phoneme isolation

a. The change of the direction from baseline until training showed that the training gives positive effect toward the score change.

b. The increasing level (observed from the last baseline until the first post training measurement) is 2 point.

c. There is no overlap data.

The RAC-S analysis result of subject after PA training explained as follows:

1. Target response: the PA ability increases, especially when identifies similarity and determine last phoneme in a word. Subject also gets the reduction of the speech error level. Subject is more able to speak the last phoneme /s/ and /l/ on a word that he can't do before.

2. Antecedents: Parents become more aware to the influence of the speech errors to the reading ability (PA). Parents play more active role to correct the way of how subject express the word when speaking and planning the academic activity outside school hours to bolster up subject's reading an writing ability.

3. Consequences: a clearer reward and punishment mechanism gives the positive influence to subject's learning progress. Subject becomes more aware the fault of any word that he said, and have willingness to change it because the consequence from the environment is already formed. At school, subject shows improvement on PA task. Teacher gave reward for those improvements, so subject becomes more confident to show the better effort to reduce his speaking error.

4. Response strength: those improve behavior going on since subject gets the integrated PA training.

Observation during the training showed that subject is able to use his attention and memory to remember the sound of a word he heard. Subject is able to apply the same way of thinking on different tasks. As an example, when he was asked to identify the last sound similarity, he will repeat the sound loudly over and over again, one by one before giving an answer. Similarly, when asked to identify the initial sound similarity, subject then repeated the word given before providing an answer. After finding the pattern, subject becomes more quickly to provide answers in the next tasks given. This is a common feature of the reading process that occurs in children in the pre-alphabetis stage. Beginning the process of reading occurs at the level of selecting instructions (selective-cue) where the children use certain nonalphabetic clues that may help them to remember a word. These clues may include the characteristics of sound or form of words (Ehri \& McCormick, 1998).

The result of observation during the training aspect of the last phoneme isolation showed that the activity of the introduction of letter-sound knowledge allows subject to recognize the sequence of letters in the word making it easier to determine the last phonemes in words. This is supported by the results of earlier research that PA training for children with speech disorder that gives the sound-letter recognition activity can sharpen the subject's perception of sound and showed that PA skills has been formed as a prelude to entering the alphabetic stage of reading development (Blischak, et al, 2004; Gillon, 2000; McNeill, Gillon, \& Dodd, 2009). 
The development also occurred in terms of ability to speak (pronounce words) and academic ability. Based on the interviews with the subject's mother indicated that after getting the speech therapy as a part of the PA training, subject becomes more clearly in saying words. Subject's confidence is also increasing, even dare to initiate conversation with a new friend in his own age whom he just met.

Developments in terms of academic obtained from interviews with subject's classroom teachers. Teachers stated that the subject is able to do tasks such as looking for picture that match the initial and final phonemes, as well as determining the initial and final phonemes in words given in the form of images. Subjects are able to do tasks quickly and independently.

The results are consistent with the results of previous study (Nation \& Snowling, 2004) which states that children's progress in learning to read related to their phonological ability. Subject in this current study experienced a more significant improvement on PA tasks involving the identification and analysis of the last phoneme. This is influenced by the character of the subject phonological disorder which is more prevalent in the replacement and removal of the final phonemes in words. The difficulties caused by the disruption experienced by the result in a lack of ability in PA, so does the effect of training on aspects of rhyme detection and isolation of the final phonemes more clearly visible than aspects of phoneme identity and initial phoneme isolation.

Lindamood and Lindamood (1975, in Ehri \& McCormick, 1998) states that children who experience difficulty in terms of phonological segmentation, should receive an adequate phonological awareness training to prepare their ability to process the alphabet written on the next stage of reading development. Special attention should be given in terms of articulation and acoustic characteristics of a sound. The position of the mouth and movements involving the lips, tongue and teeth is a basic ability in finding the sound segments in words. Then it can be concluded that in addition to getting training in phonological awareness cannot be separated (as important as) with articulation exercises, especially in children with phonological disorders.

Strong connection between PA interventions and articulation improvement demonstrated by some results of research which confirms that the relationship between phonological awareness intervention and articulation improvement occurred in both directions which affect each other and equally had positive impact on the ability of children who have speech disorders. Subjects who had impaired speech showed improvement on articulation after getting a phonological awareness training (Blischak, 2004; Gillon, 2000, 2005). Phonological awareness training can improve children's ability to process the sound they heard. Children become aware of the number and order of the sound of the word is heard so that helps children to recognize and correct speech errors. While the exercise in aticulation which is generally included in phonological awareness training can improve the ability of expressive phonology in children (Gillon, 2000). Then it can be concluded that phonological awareness training on children who have speech difficulty is absolutely have to insert the articulation exercise (speech therapy) in it.

\section{Conclusion}

Word-sound knowledge training can improve PA ability in child with PD. The PD characteristic subject showed is an articulation error in the last phoneme $/ \mathrm{k} /, / \mathrm{l} /, / \mathrm{n} /, / \mathrm{ng} /, / \mathrm{s} /$, and $/ \mathrm{t} /$ which often missed/not clearly heard. PA ability was markedly improved in identifying and analyzing the last phoneme in word. Integration with speech therapy given in training was also decreasing the articulation error level in word contains the last phoneme /s/ and /l/. The training effect was more significant on the aspect of rhyme detection and last phoneme isolation, it was also decreasing the articulation error level in the words contain the last phoneme of $/ \mathrm{s} /$ and /l/. These findings showed that the intervention had greater effect on the PA aspect and phonemes errored in speech which matched the characteristic of PD that subject had.

The limitation of this research as discussed earlier, were the lack of time management and the implementation of behavior modification procedure which is not facilitate the extinction of the reinfocer after the expected behavior showed. Factors associated with the success of the training are the training material, trainer, and the process of the training itself.

\section{References}

American Psychiatric Association. (2000). Diagnostic and Statistical Manual of Mental Disorders. Fourth Edition - Text Revision. Washington DC: American Psychiatric Association.

Ashby, Jane. (2010). Phonology is fundamental in skilled reading: Evidence from ERPs. Psychonomic Bulletin \& Review, 17 (1), 95-100. 
Blischak, D. M., Shah, S. D., Lombardino, L. J., \& Chiarela, K. (2004). Effects of phonemic awareness instruction on the encoding skills of children with severe speech impairment. Disability and Rehabilitation, 26, 1295-1304.

Bowen, C. (1998). Developmental phonological disorders. Downloaded on Friday, January 22, 2010 from http://www.speech-language-therapy.com/parentinfo.html.

Byrnes, J. P. (1996). Cognitive development and learning in instructional contexts. Boston: Allyn \& Bacon.

Cirrin, F. M., \& Gillam, R. B. (2008). Language intervention practices for school-age children with spoken language disorders: A systematic review. Language, Speech, and Hearing Services in Schools, 39, S110-S137.

Davidson, T. (2003). Phonological disorder. Downloaded on Friday, January 22, 2010 from http://www.minddisorders.com/Ob-Ps/Phonological-disorder.html.

Ehri, L. C., \& McCormick, S. (1998). Phases of word learning: Implications for instruction with delayed and disabled readers. Reading \& Writing Quarterly, 14, 135-164.

Gillon, G. T. (2000). The efficacy of phonological awareness intervention for children with spoken language impairment. Language, Speech \& Hearing Services in Schools, 31, 126-141.

Gillon, G. T. (2007). Phonological awareness assessment probes for preschool children. Downloaded on Thursday, March 11, 2010 from http://www.education.canterbury.ac.nz/people/gillon/resources.shtml.

Gillon, G. T. (2008). The Gillon Phonological Awareness Training Programme: An intervention programme for children at risk for reading disorder. Canterbury: Department of Communication Disorders, College of Science, University of Canterbury.

Hipfner-Boucher, Kathleen, et.al. (2014). Relationship between preschoolers' oral language and phonological awareness. First Language, 34 (2), 178-197.

Holm, A., Farrier, F., \& Dodd, B. (2008). Phonological awareness, reading accuracy and spelling ability of children with inconsistent phonological disorder. International Journal of Language \& Communication Disorders, 43, 300-322.

McNeill, B. C., Gillon, G. T., \& Dodd, B. (2009). Effectiveness of an integrated phonological awareness approach for children with Childhood Apraxia of Speech (CAS). Child Language Teaching and Therapy, 25, 341-366.

Nation, K., \& Snowling, M. J. (2004). Beyond phonological skills: broader language skills contribute to the development of reading. Journal of Research in Reading, 27, 342-356.

Picard, C. J. (2002). Phonological awareness for the speech/language pathologists and their educational partners. Louisiana: Louisiana Department of Education.

Puspitasari, N. (2010). Laporan Praktik Kerja Profesi Bidang Psikologi Pendidikan Tingkat TK (Unpublished). Yogyakarta: UGM Faculty of Psychology.

Rvachew, S., \& Grawburg, M. (2006). Correlates of phonological awareness in preschoolers with speech sound disorders. Journal of Speech, Language, and Hearing Research, 49, 74-87.

Rvachew, S. (2007). Phonological processing and reading in children with speech sound disorders. American Journal of Speech-Language Pathology, 16, 260-270.

Sessiani, L. A. (2010). Laporan Praktik Kerja Profesi Bidang Psikologi Pendidikan Tingkat TK (unpublished). Yogyakarta: UGM Faculty of Psychology.

Snowling, M. J., \& Stackhouse, J. (2006). Dyslexia, speech, and language - a practitioner's handbook - second edition. London: Whurr Publishers.

Sunanto, J., Takeuchi, K., \& Nakata, H. (2005). Pengantar penelitian dengan subyek tunggal. Tsukuba: CRICED University of Tsukuba.

Sundel, M., \& Sundel, S. S. (2005). Behavior change in the human services - behavioral and cognitive principles and applications. Thousand Oaks: Sage Publications.

Sutherland, D., \& Gillon, G.T. (2005). Assessment of phonological representations in children with speech impairment. Language, Speech, and Hearing Services in Schools, 36, 294-307. 
Tim Penyusun Kamus Pusat Pembinaan dan Pengembangan Bahasa. (1999). Kamus Besar Bahasa Indonesia. Jakarta: Balai Pustaka.

Westwood, P. S. (2001). Reading and learning difficulties: Approaches to teaching and assessment. Camberwell: Acer Press.

Wulansari, A. J. (2009). Pelatihan imitasi suara untuk anak yang mengalami gangguan fonologi. Thesis. (Unpublished). Yogyakarta: UGM Faculty of Psychology. 